\title{
Synthesis of Ladder Silsesquioxanes by in situ Polycondensation of Cyclic Tetravinylsiloxanetetraols
}

\author{
Anna Kowalewska • Maria Nowacka
}

Received: 4 February 2014 / Accepted: 2 June 2014 / Published online: 30 December 2014

(C) Springer Science+Business Media Dordrecht 2014

\begin{abstract}
Functionalized tetrahydroxy-cyclotetrasiloxanes are very attractive precursors of tetrasiloxane ring systems in linear silsesquioxanes (LPSQs). Vinyl groups are especially important since they can be employed for various chemical transformations (e.g. hydrosilylation, metathesis reactions, thiol-ene addition). However, isolation of such highly reactive species bearing small side substituents at silicon atoms with high yield is challenging. We overcame the problem by in situ condensation of 2,4,6,8-tetrahydroxy2,4,6,8-tetravinyl-cyclotetrasiloxanes, derived from potassium organosiloxanolate $\left\{\left(\mathrm{K}^{+}\right)_{4}\left[\mathrm{ViSi}(\mathrm{O}) \mathrm{O}^{-}\right]_{4}\right\} \mathrm{nL}(\mathrm{L}=$ $\mathrm{EtOH}, \mathrm{H}_{2} \mathrm{O}$ ). Oligomeric LPSQ materials having a siloxane backbone with ladder structure and functionalized with side vinyl groups were thus prepared. Hexamethyldisilazane was employed for chain termination. The liquid materials show remarkably good solubility in organic solvents. They were isolated and characterized using spectroscopic methods. Information on their structure and molecular masses was derived from MALDI-TOF and MALLS measurements. Size exclusion chromatography (RI detection, volume of elution measurements) was also used. The products were characterized by wide-angle X-Ray diffraction measurements (WAXS) and their thermal characteristics (TGA and DSC) were obtained.
\end{abstract}

Keywords Ladder oligosilsesquioxanes . Cyclosilanolate $\cdot$ Polycondensation $\cdot$ MALDI-TOF

Electronic supplementary material The online version of this article (doi:10.1007/s12633-014-9209-z) contains supplementary material, which is available to authorized users.

A. Kowalewska $(\bowtie) \cdot$ M. Nowacka

Centre of Molecular and Macromolecular Studies, Polish Academy of Sciences, 90-363 Łódź, Sienkiewicza 112, Poland e-mail: anko@cbmm.lodz.pl

\section{Introduction}

Linear, ladder-type silsesquioxanes (LPSQs) can be regarded as an intermediate between polyhedral silsesquioxanes (POSS) and single-chain linear siloxanes. They are of increasing interest due to their excellent physiochemical properties, high thermal stability and good mechanical performance. Their hybrid structure (inorganic double chain backbone and organic side groups) results in a low dielectric constant. They are not only thermally- and chemically resistant but also well soluble in organic solvents and show good film-forming properties, so they are attractive as functional materials [1].

The regularity of the LPSQ backbone depends greatly on the methods used for their preparation and can be complicated by uncontrolled side reactions. Ladder-type silsesquioxanes were first reported by Brown et al. [2] Their synthesis was based on the use of highly reactive trifunctional silanes $\operatorname{RSiX}_{3}(\mathrm{X}=\mathrm{Cl}$ and $\mathrm{OR})$ as monomers and gave LPSQs with high molecular weight, but of ill-defined architecture. The number of structural defects in polysilsesquioxane materials increases with increasing molecular weight until random networks are formed [3]. The resulting degree of randomness depends both on the nature of the substituent at the silicon atom and the reaction conditions [4]. Several synthetic protocols for the preparation of ladder polysilsesquioxanes have been developed more recently [5, 6]. Efforts are focused on the control of the structure of the double siloxane backbone. The molecular design of the precursor was found to be of special importance. Weak supramolecular interactions (H-bonding or $\pi-\pi$ stacking) between silanol groups and/or template molecules help in the synthesis of well-defined LPSQs via stepwise coupling and condensation polymerization [7]. The procedure is based on 
the template-directed formation of a pseudo-ladder superstructure. It made possible the synthesis of soluble ladder polyphenylsiloxanes having triple [8] and even quadruple [9] chains. High-molecular-weight ladder polyphenylsilsesquioxanes of regular structure were also synthesized by use of "monomer self-organization-lyophilizationsurface-confined polycondensation" [7]. Well-defined ladder poly(methylphenylsilsesquioxanes) were obtained as well via nonhydrolytic condensation [10]. Polysilsesquioxanes can be also obtained by condensation of specific tetrasiloxane precursors such as disiloxanes $\left[\mathrm{RSiX}_{2}\right]_{2} \mathrm{O}$ and cyclotetrasiloxanes $[\mathrm{RXSiO}]_{4}$ that help the formation of a true ladder structure. Linear ladder silsesquioxanes have been synthesized from sila-functionalized $\left[\mathrm{RSiXO}_{4}\right.$ $(\mathrm{R}=\mathrm{Me}, \mathrm{Ph} ; \mathrm{X}=\mathrm{H}, \mathrm{OEt}, \mathrm{NCO})$ [11, 12]. Polycondensation of all-cis or cis-trans-cis isomers of cyclic tetrasilanols [13] or isocyanates [14] gives linear polymers of high regularity and defined tacticity. Unno et al. reported the stepwise stereo-controlled condensation of cyclosilanols for the preparation of tricyclic [15] pentacyclic [16] bi-, tri-, tetra- and pentacyclic ladder siloxanes with an all-anti conformation [17], nonacyclic [18] as well as heptacyclic ladder siloxanes and methyl-substituted ladder polysilsesquioxanes [19]. Ladder oligosilsesquioxanes of low molecular weight were also prepared by controlled condensation of an isocyanate functionalized cyclosiloxane precursor: cis,trans, cis-[MeSi(NCO)O $]_{4}$ $[20,21]$.

However, the reported silsesquioxanes obtained with $[\mathrm{RSi}(\mathrm{OH}) \mathrm{O}]_{4}$ bear only simple $\mathrm{Me}$ or $\mathrm{Ph}$ side groups. The presence of reactive pendant groups would make them more useful as versatile functional materials. Applications of ladder polysilsesquioxanes with vinyl or chloropropyl groups could be of high interest. Our aim was the synthesis of soluble well-defined LPSQs functionalized with vinyl side groups capable of various chemical transformations. We have found that, under specific conditions, condensation of silanol groups in 2,4,6,8-tetrahydroxy2,4,6,8-tetrafunctional cyclosiloxanes, prepared in situ from the respective potassium silanolates, can give oligomeric materials with ladder structure (Scheme 1). Reference materials were prepared by simple hydrolytic condensation of $\mathrm{ViSi}(\mathrm{OEt})_{3}$ in the presence of $\mathrm{K}_{2} \mathrm{CO}_{3}$ [1] and stepwise coupling polymerization [22]. The structure and the properties of the resulting materials were analyzed by use of NMR, XRD, TGA, DSC, SEC (MALLS and RI) and MALDI-TOF.

\section{Experimental}

\subsection{Materials}

Reagents [triethoxyvinylsilane (Aldrich, $97 \%$ ), trichlorovinylsilane (Aldrich, $\geq 97 \%$ ), chlorotrimethylsilane (Fluka Analytical, purum, $\geq 98 \%$, GC), hexamethyldisilazane (Fluka Analytical, $\geq 98 \%$, GC), potassium hydroxide (Aldrich, ACS reagent, $\geq 85$, pellets), acetic acid (Aldrich, $\geq 99 \%$, ReagentPlus ${ }^{\circledR}$ ), potassium carbonate $\mathrm{K}_{2} \mathrm{CO}_{3}$ (POCH, pure p.a.), magnesium sulfate (VI) $\mathrm{MgSO}_{4}$ (Chempur, pure), sodium chloride $\mathrm{NaCl}$ (Chempur, pure p.a.)] were used as received. Triethylamine $(\mathrm{POCH}$, pure p.a.) was dried over $\mathrm{KOH}$ and distilled before use, p-phenylenediamine (pPDA) (Aldrich, $\geq 99 \%, \mathrm{GC} / \mathrm{NT}$ ) was sublimed before use.

Solvents [ethyl acetate (Chempur, pure p.a.), toluene (Chempur, pure p.a.), hexane (Aldrich, Chromasolv ${ }^{\circledR}$ for HPLC, $\geq 97 \%$, GC), pentane (Chempur, pure p.a.), DMF (Chempur, pure p.a.) acetonitrile (Chempur, pure p.a.) tetrahydrofuran (THF) (Chempur, pure p.a.), dichloromethane (Chempur, pure p.a.), ethanol (Polmos, $95 \%$ ), methanol (Chempur, pure p.a.)], were purified according to literature procedures [23].

\subsection{Instrumentation}

Liquid state NMR $\left({ }^{1} \mathrm{H},{ }^{13} \mathrm{C}\right.$ and ${ }^{29} \mathrm{Si}$ NMR $)$ spectra of the precursors and condensed soluble materials in $\mathrm{CDCl}_{3}$ were recorded on a Bruker DRX-500 $\mathrm{MHz}$ spectrometer, with TMS as the reference. Solid-state ${ }^{29} \mathrm{Si}$ NMR spectra were recorded on a AV-400 Bruker spectrometer at $59.627 \mathrm{MHz}$ with high power decoupling (hpdec) of direct polarization that enabled quantitative integration. The peak positions were referenced to the signal of $\mathrm{Q}_{8} \mathrm{M}_{8}$ (trimethylsilyl ester of cubic octameric silicate) as standard.

Phase transitions of polymers were studied by differential scanning calorimetry (DSC) technique (DuPont 2000 thermal analysis system). Thermograms were taken for samples (sealed in aluminium pans) quenched rapidly from the melt (room temperature) and then heated at the rate of $10{ }^{\circ} \mathrm{C} /$ min from $-155{ }^{\circ} \mathrm{C}$ to $50{ }^{\circ} \mathrm{C}$. The sample was kept at $50{ }^{\circ} \mathrm{C}$ for $3 \mathrm{~min}$ to destroy any thermal history. Subsequently, it was quenched to $-155{ }^{\circ} \mathrm{C}$ and heated again at $10{ }^{\circ} \mathrm{C} /$ min to $100{ }^{\circ} \mathrm{C}$. Thermogravimetric measurements

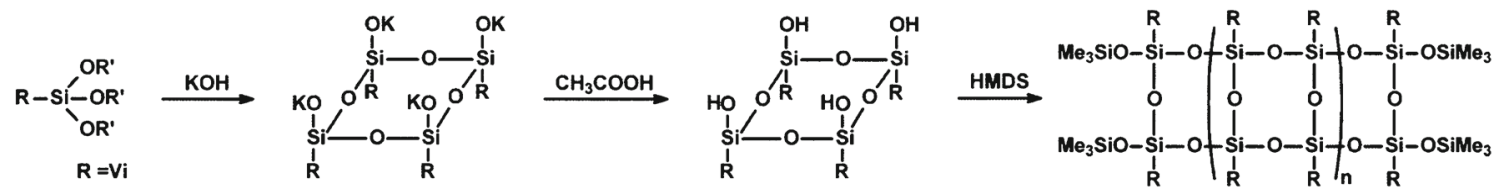

Scheme 1 Synthesis of oligomeric Vi-LPSQs by in situ polycondensation method 
were performed using a Hi-Res TGA 2950 Thermogravimetric Analyzer (TA Instruments) in a nitrogen atmosphere (heating rate $10{ }^{\circ} \mathrm{C} / \mathrm{min}$, resolution 3 , sensitivity 3 ).

Mass spectrometric measurements (MALDI-TOF) were made on a Voyager-Elite (PerSeptive Biosystems, USA) time-of-flight instrument equipped with a pulsed $\mathrm{N}_{2}$ laser (337 nm, 4-ns pulse width) and time-delayed extraction ion source. An accelerating voltage of $20 \mathrm{kV}$ was applied. Mass spectra were recorded in the linear positive ion mode using 1,8-dihydroxy-9-anthracenone (ditranol, DT) as the matrix and $\mathrm{LiCl}$ or $\mathrm{CF}_{3} \mathrm{COOK}$ as the cationization agents.

For size exclusion chromatography (SEC) an Agilent 1100 series chromatograph composed of degasser, pump, and autosampler was used. Two PL Gel $5 \mu \mathrm{m}$ MIXED-C columns $(7.8 \times 300 \mathrm{~mm})$ were employed in a series (temperature $27^{\circ} \mathrm{C}$ ). RI (OPTILAB T-rex, Wyatt) and MALLS (DAWN HEOS, II, Wyatt, $\lambda=682 \mathrm{~nm}$ ) were used as detectors. The mobile phase was dichloromethane at a flow rate of $0.8 \mathrm{~mL} / \mathrm{min}$. Samples (concentration of polymers: $7 \mathrm{mg} / \mathrm{mL}$ ) were dissolved in $\mathrm{CH}_{2} \mathrm{Cl}_{2}$ and passed through $0.2 \mu \mathrm{m}$ pore size SRP membrane filters. Injection volumes of the sample solutions were $100 \mu \mathrm{L}$. Molecular masses were derived from a calibration curve based on polystyrene standards and Astra 4.90.07 software was used to treat the data.

WAXS (wide angle-X-ray scattering) was used for the determination of sample structure. The experiments were made on a Philips X'Pert Pro MD diffractometer with $\mathrm{Cu} \mathrm{K} \alpha 1$ line radiation monochromatized by a $\mathrm{Ge}(111)$ monochromator and standard Bragg-Brentano geometry with $\theta-2 \theta 0.008^{\circ}$ step size and $5-90^{\circ} 2 \theta$ range.

\subsection{Synthetic Procedures}

\subsubsection{Potassium Tetravinyltetracyclosiloxanolate}

Potassium tetravinyltetracyclosiloxanolate was prepared according to the literature procedure [24]. Triethoxyvinylsilane $(0.235 \mathrm{~mol})$ and a mixture of anhydrous ethanol $(30 \mathrm{ml})$ and water $(0.4 \mathrm{ml})$ were simultaneously added drop-wise to a mixture of hexanes $(220 \mathrm{ml})$ and $\mathrm{KOH}(0.276 \mathrm{~mol})$ in a round-bottom flask equipped with a magnetic stirrer and a thermometer. The rate of addition was adjusted so that the temperature in the reaction flask did not exceed $24^{\circ} \mathrm{C}$. Once the addition was complete, the reaction mixture was stirred for another $1.5 \mathrm{~h}$ at room temperature then it was cooled to $0-4{ }^{\circ} \mathrm{C}$ in a water/ice bath for 5 hours. The fine white solid that precipitated from the solution was filtered off under reduced pressure, washed with large volumes of $\mathrm{n}$-pentane and dried under high vacuum (1 Torr) at room temperature to constant weight. The white crystalline powder was obtained in a yield of $2.37 \mathrm{~g}(76 \%)$. It was stable for months at low temperatures.
Elemental analysis: Calculated [\%] for $\left\{\left(\mathrm{K}^{+}\right)_{4}[\mathrm{ViSi}\right.$ (O)O- $\left.]_{4}\right\} \mathrm{EtOH} 5 \mathrm{H}_{2} \mathrm{O}, \mathrm{C}_{8} \mathrm{H}_{12} \mathrm{Si}_{4} \mathrm{O}_{8} \mathrm{~K}_{4}$ EtOH $5 \mathrm{H}_{2} \mathrm{O}: \mathrm{C}=$ 18.74; $\mathrm{H}=4.40$; Found [\%]: $\mathrm{C}=19.0 ; \mathrm{H}=5.0$.

${ }^{13} \mathrm{C}$ CP MAS NMR, $\delta$ [ppm]: $129.4(=\mathrm{CH}-) ; 135.1$ $\left(=\mathrm{CH}_{2}\right)$

${ }^{29} \mathrm{Si}$ CP MAS NMR, $\delta$ [ppm]: -82.2

\subsubsection{Preparation of Oligomeric Vi-LPSQs}

by in situ-Polycondensation of Cyclic

Tetravinylsiloxanetetraol

Procedure A Solid potassium tetravinyltetracyclosiloxanolate $(15.6 \mathrm{mmol})$ was slowly added to a cooled $\left(0-5^{\circ} \mathrm{C}\right)$ solution of acetic acid $(63 \mathrm{mmol})$ in ethyl acetate $(420 \mathrm{ml})$. The temperature of the reaction mixture was kept below $10{ }^{\circ} \mathrm{C}$ during the addition of cyclosiloxanolate and for another 30 minutes once the addition was completed. Potassium acetate was filtered off and the filtrate was left for 30 minutes to warm up to room temperature. Hexamethyldisilazane $(81.5 \mathrm{mmol})$ and $\mathrm{MgSO}_{4}(10 \mathrm{~g})$ were then added to the reaction mixture, which was stirred under reflux. The progress of reaction was monitored by MALDI-TOF spectrometry. The reaction was continued until condensation of silanol groups was complete. The mixture was then allowed to cool, $\mathrm{MgSO}_{4}$ was filtered off, the solution was passed through a short silica plug and all volatiles were removed at room temperature under high vacuum. The product was a viscous, colorless liquid.

Procedure $B$ Acetic acid was added dropwise to a cooled $\left(0-5{ }^{\circ} \mathrm{C}\right)$ suspension of potassium tetravinyltetracyclosiloxanolate in a reaction solvent. The temperature of the mixture was kept below $10{ }^{\circ} \mathrm{C}$ for another 30 minutes once the addition was completed. Potassium acetate was filtered off and the filtrate was left for 30 minutes to warm up to room temperature. Hexamethyldisilazane and $\mathrm{MgSO}_{4}$ were added to the reaction mixture, which was then heated under reflux with stirring to achieve complete condensation of silanol groups. The progress of reaction was monitored with MALDI-TOF spectrometry. The reaction mixture was allowed to cool, $\mathrm{MgSO}_{4}$ was filtered off, the solution was passed through a short silica plug, and all volatiles were removed at room temperature under high vacuum. The product was a viscous, colorless liquid.

${ }^{1} \mathrm{H}$ NMR $\left(\mathrm{CDCl}_{3}\right), \delta[\mathrm{ppm}]: 0.08\left(\mathrm{OSiMe}_{3}\right), 5.91$ $\left(-\mathrm{CH}=\mathrm{CH}_{2}\right)$

${ }^{13} \mathrm{C}$ NMR $\left(\mathrm{CDCl}_{3}\right), \delta[\mathrm{ppm}]: 0.3\left(\mathrm{OSiMe}_{3}\right), 129.9$ $(=\mathrm{CH}-), 135.5\left(=\mathrm{CH}_{2}\right)$

${ }^{29} \mathrm{Si}$ NMR $\left(\mathrm{CDCl}_{3}\right) ; \delta \quad[\mathrm{ppm}]:-81.0 \quad\left(\mathrm{H}_{2} \mathrm{C}=\mathrm{CH}-\right.$ $\left.\mathrm{SiO}_{3 / 2}\right), 10.5\left(\mathrm{OSiMe}_{3}\right)$ 


\subsubsection{Preparation of Vi-LPSQs by Stepwise Coupling Polymerization}

Vi-LPSQ polymer of high molecular mass was prepared in $56 \%$ yield using a previously described procedure [22].

${ }^{1} \mathrm{H}$ NMR $\left(\mathrm{CDCl}_{3}\right), \delta$ [ppm]: $0.07\left(\mathrm{OSiMe}_{3}\right), 5.92$ $\left(-\mathrm{CH}=\mathrm{CH}_{2}\right)$

${ }^{13} \mathrm{C}$ NMR $\left(\mathrm{CDCl}_{3}\right), \delta$ [ppm]: $0.45\left(\mathrm{OSiMe}_{3}\right), 130.0$ $(=\mathrm{CH}-), 134.9\left(=\mathrm{CH}_{2}\right)$

${ }^{29} \mathrm{Si}$ NMR $\left(\mathrm{CDCl}_{3}\right) ; \delta \quad[\mathrm{ppm}]:-81.0 \quad\left(\mathrm{H}_{2} \mathrm{C}=\mathrm{CH}-\right.$ $\left.\mathrm{SiO}_{3 / 2}\right), 10.0\left(\mathrm{OSiMe}_{3}\right)$

SEC (RI): $\mathrm{Mn}=34$ 000, $\mathrm{Mw}=274$ 000, $\mathrm{PDI}=8.1$, (MALLS): $\mathrm{Mn}=1460$ 000, $\mathrm{Mw}=3330$ 000, $\mathrm{PDI}=2.3$.

\subsubsection{Preparation of Branched Polysilsesquioxane by Polycondensation of $\mathrm{ViSi}(\mathrm{OEt})_{3}$}

The branched analogue of linear Vi-LPSQs was prepared according to the literature procedure [1]. The product was obtained as an insoluble solid (reaction yield: $90 \%$ ).

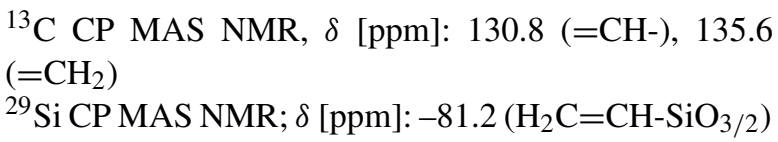

\section{Results and Discussion}

\subsection{Monomer Synthesis and Polycondensation}

The use of hydroxyl-substituted cyclic siloxane stereoisomers is a precondition for the synthesis of linear oligo- and polysilsesquioxanes of stereoregular structure. However, their isolation from the crude reaction mixture is difficult and the product is obtained with a very low yield. For example, a mixture of four stereoisomers was prepared by hydrolysis of the hydride precursor, $[\mathrm{MeSi}(\mathrm{H}) \mathrm{O}]_{4}$ catalyzed by $\mathrm{Pd} / \mathrm{C}_{\text {act }}[13]$. Cis-trans-cis-tetraol was isolated using specific recrystallization protocol with about $8 \%$ yield and polycondensed in the presence of $\mathrm{K}_{2} \mathrm{CO}_{3}$ as a catalyst, resulting in a ladder-like product of cis-syndiotactic conformation $[13,25]$. Unfortunately, the method is not suitable for some monomers (e.g. Vi-substituted ones).

Tetraorganocyclotetrasiloxanolates [26] are of interest as precursors of cyclic siloxanetetraols. Removal of metal ions from cyclic tetrametallasiloxanes by dilute aqueous hydrochloric acid is a convenient preparative method resulting in high-yield (80-90\%) formation of stereoregular oligophenysiloxane polyols: all-cis- $[\mathrm{PhSi}(\mathrm{OH}) \mathrm{O}]_{4}$, allcis-[PhSi $(\mathrm{OH}) \mathrm{O}]_{6}$, tris-cis-tris-trans- $[\mathrm{PhSi}(\mathrm{OH}) \mathrm{O}]_{12}$ [27]. Analogously, 1,3,5,7-tetramethyl-1,3,5,7-tetrahydroxy-cyclo tetrasiloxane was obtained from all-cis-(tetrapotassium tetramethylcyclotetrasiloxanolate) $\left(\mathrm{K}^{+}\right)_{4}\left[\mathrm{MeSi}(\mathrm{O}) \mathrm{O}^{-}\right]_{4} 3 \mathrm{~L}$
( $\mathrm{L}=\mathrm{EtOH}, \mathrm{H}_{2} \mathrm{O}$ ) [28]. Two crystalline isomeric forms (allcis and cis-trans-cis) were isolated in good yield (respectively, $29 \%$ and $60 \%$ ).

Nevertheless, reports concerning siloxanetetraols functionalized with reactive side groups are scarce as yet. Quite recently, Sparks et al. reported the synthesis of cyclic tetravinylsiloxanetetraol $[\mathrm{ViSi}(\mathrm{OH})]_{4}$ by acidic hydrolysis of potassium $c i s$-tetravinyltetrasiloxanolate in ethyl acetate [24]. The authors isolated the all-cis isomer and described it as reasonably stable, but the yield was not given. The authors presented a ${ }^{29} \mathrm{Si}$ NMR spectrum displaying a single peak at $-74 \mathrm{ppm}$ as well as size exclusion chromatography diagrams for the isolated product.

We were not able to obtain pure $[\mathrm{ViSi}(\mathrm{OH}) \mathrm{O}]_{4}$ using the reported procedure. Partial reduction of volume of the crude reaction mixture by evaporation of the liquid components (high vacuum/room temperature) did not give crystalline products but a range of viscous oils. Owing to the silanol functions in the product, the materials were not stable and cross-linked after several days on the bench at room temperature. However, $[\mathrm{ViSi}(\mathrm{OH})]_{4}$ was indeed formed during the acidic hydrolysis of the silanolate, as confirmed by spectroscopic analysis. $\left[\mathrm{ViSi}\left(\mathrm{OSiMe}_{3}\right) \mathrm{O}_{4}\right.$ was detected (NMR, MS-CI+) as the only derivative after silylation of $[\mathrm{ViSi}(\mathrm{OH})]_{4}$ with an excess of bis(trimethylsilyl)acetamide (BSA) in the crude reaction mixture (Fig. 1).

We thus decided to convert $[\mathrm{ViSi}(\mathrm{OH}) \mathrm{O}]_{4}$ into oligomeric or polymeric ladder vinylsilsesquioxanes, in situ in the reaction mixture and block the reactive $\mathrm{SiOH}$ groups with $\mathrm{SiMe}_{3}$ endgroups by treatment with hexamethyldisilazane (HMDS). Potassium siloxanolate $\left\{\left(\mathrm{K}^{+}\right)_{4}\left[\mathrm{ViSi}(\mathrm{O}) \mathrm{O}^{-}\right]_{4}\right\} \mathrm{nL}\left(\mathrm{L}=\mathrm{EtOH}, \mathrm{H}_{2} \mathrm{O}\right)$ was converted into the corresponding cyclosiloxane tetrol by the removal of potassium ion with concentrated $\mathrm{CH}_{3} \mathrm{COOH}$ in an anhydrous solvent. The reaction mixture was refluxed

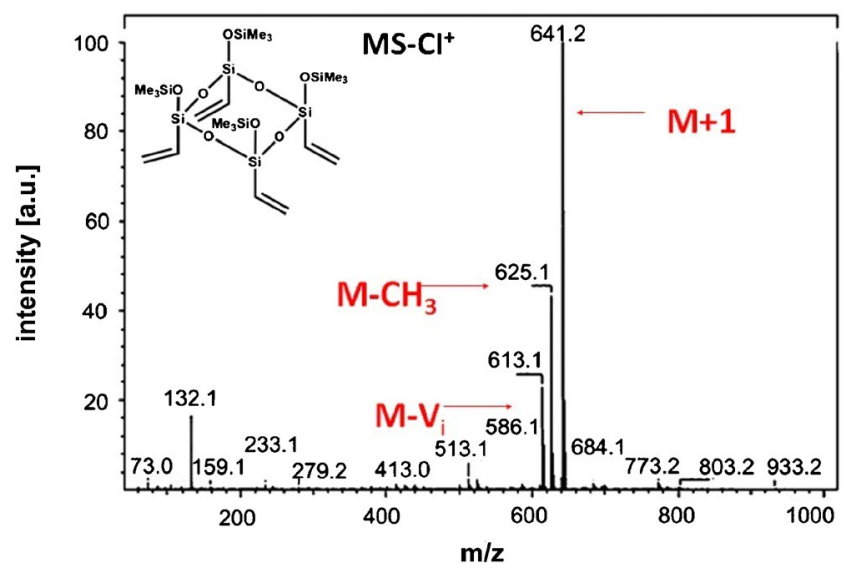

Fig. $1 \mathrm{MS}^{-\mathrm{CI}^{+}}$of $\left[\mathrm{ViSi}\left(\mathrm{OSiMe}_{3}\right) \mathrm{O}\right]_{4}$ obtained by silylation with BSA 
Table 1 Reaction parameters and characteristics of the products obtained by in situ condensation of tetravinylsiloxanetetraol (molar ratio $\left[\mathrm{CH}_{3} \mathrm{COOH}\right] /[$ potassium silanolate $\left.]=4.1\right)$

\begin{tabular}{|c|c|c|c|c|c|c|c|c|c|c|c|c|}
\hline Entry & $\mathrm{x}$ & $\mathrm{y}$ & $\mathrm{a}_{0}\left[\mathrm{~mol} / \mathrm{dm}^{3}\right]$ & $\mathrm{b}$ & Solvent & $\mathrm{T}\left[{ }^{\circ} \mathrm{C}\right]$ & $\mathrm{t}$ [days] & $\mathrm{Mn}$ & $\mathrm{PDI}_{1}$ & $\mathrm{Mw}$ & $\mathrm{PDI}_{2}$ & $\mathrm{Y}[\%]$ \\
\hline $1-1$ & A & + & 39.0 & 3.98 & toluene & 110 & 7 & 1100 & 1.6 & 6700 & 1.7 & 26.7 \\
\hline $1-2$ & A & + & 37.1 & 3.98 & $\mathrm{CH}_{3} \mathrm{COOEt}$ & 78 & 7 & 1000 & 1.2 & 3200 & 1.6 & 67.5 \\
\hline $1-3$ & A & + & 37.1 & 3.98 & $\mathrm{CH}_{3} \mathrm{COOEt}$ & 78 & 6 & 1000 & 1.4 & 3000 & 1.3 & 71.4 \\
\hline $1-4$ & A & + & 32.3 & 3.98 & $\mathrm{MeCN}$ & 82 & 4 & - & - & - & - & 19.4 \\
\hline $1-5$ & B & - & 32.3 & 3.98 & $\mathrm{CH}_{3} \mathrm{COOEt}$ & 78 & 3 & 800 & 1.2 & 3300 & 1.5 & 27.4 \\
\hline $1-6$ & B & + & 32.3 & 3.98 & $\mathrm{CH}_{3} \mathrm{COOEt}$ & 78 & 3 & 300 & 1.6 & - & - & 37.9 \\
\hline $1-7$ & B & - & 48.5 & 3.98 & $\mathrm{CH}_{3} \mathrm{COOEt}$ & 78 & 3 & 400 & 1.5 & 4100 & 1.3 & 25.8 \\
\hline $1-8$ & B & - & 32.3 & 1.00 & toluene & 110 & 3 & 500 & 2.3 & 1500 & 1.1 & 87.9 \\
\hline $1-9$ & $\mathrm{~B}$ & - & 32.3 & 2.00 & toluene & 110 & 3 & 500 & 2.4 & 2700 & 1.1 & 83.1 \\
\hline $1-10$ & B & - & 32.3 & 3.98 & toluene & 110 & 3 & 1300 & 1.4 & - & - & 17.7 \\
\hline $1-11$ & B & + & 32.3 & 3.98 & toluene & 110 & 3 & 600 & 2.7 & 1600 & 2.3 & 21.0 \\
\hline $1-12$ & B & - & 32.3 & 4.79 & toluene & 110 & 4 & 1200 & 1.4 & - & - & 12.9 \\
\hline $1-13$ & B & - & 48.5 & 3.98 & toluene & 110 & 3 & 700 & 2.1 & 5900 & 1.6 & 19.4 \\
\hline $1-14$ & B & - & 97.0 & 3.98 & toluene & 110 & 3 & 500 & 2.4 & 5000 & 1.4 & 17.7 \\
\hline $1-15$ & B & + & 97.0 & 3.98 & toluene & 110 & 3 & 600 & 2.3 & 1700 & 1.9 & 33.1 \\
\hline $1-16$ & B & - & 32.3 & 3.98 & hexane & 70 & 3 & 500 & 1.7 & - & - & 9.7 \\
\hline $1-17$ & B & - & 74.6 & 4.95 & $\mathrm{Et}_{2} \mathrm{O}$ & 24 & 13 & 1100 & 1.2 & - & - & 45.2 \\
\hline $1-18$ & B & - & 32.3 & 3.98 & THF & 66 & 3 & - & - & - & - & 32.3 \\
\hline $1-19$ & B & - & 32.3 & 3.98 & $\mathrm{EtOH}$ & 78 & 3 & - & - & - & - & - \\
\hline $1-20$ & B & - & 32.3 & 3.98 & DMF & 150 & 3 & - & - & - & - & 87.1 \\
\hline $1-21$ & B & - & 32.3 & 3.98 & $\mathrm{MeCN}$ & 82 & 3 & 2000 & 1.2 & 1400 & 1.8 & 40.3 \\
\hline
\end{tabular}

$\mathrm{a}_{0}$ initial concentration of potassium silanolate $[\mathrm{ViSi}(\mathrm{OK}) \mathrm{O}]_{4}$ in the reaction mixture

$\mathrm{b}$ - molar ratio [HMDS]/[potassium silanolate]

$\mathrm{x}$ - synthetic procedure

$\mathrm{y}-\mathrm{CH}_{3} \mathrm{COOK}$ removed by filtration

$\mathrm{T}$ - temperature

$\mathrm{t}$ - reaction time

$\mathrm{Mn}, \mathrm{PDI}_{1}$ respectively molecular mass and polydispersity derived from SEC-RI

$\mathrm{Mw}, \mathrm{PDI}_{2}$ molecular weight and polydispersity derived from SEC-MALLS

$\mathrm{Y}$ - reaction yield calculated for the amount of $[\mathrm{ViSi}(\mathrm{OK}) \mathrm{O}]_{4}$

with HMDS to give the Vi-LPSQs. The condensation was carried out in solvents of various polarities $\left(\mathrm{Et}_{2} \mathrm{O}\right.$, $\mathrm{CH}_{3} \mathrm{COOEt}$, toluene, hexane, THF, EtOH, DMF, MeCN) (Table 1) and the reaction was followed using MALDI-TOF spectroscopy.
The procedure (Scheme 2) does not involve addition of any catalysts used typically for the condensation of silanols. However, there are many basic species in the reaction mixture. HMDS is a very mild base, much weaker than most organic amines [29]. It has low Lewis basicity $(\mathrm{pKa}=7.55)$
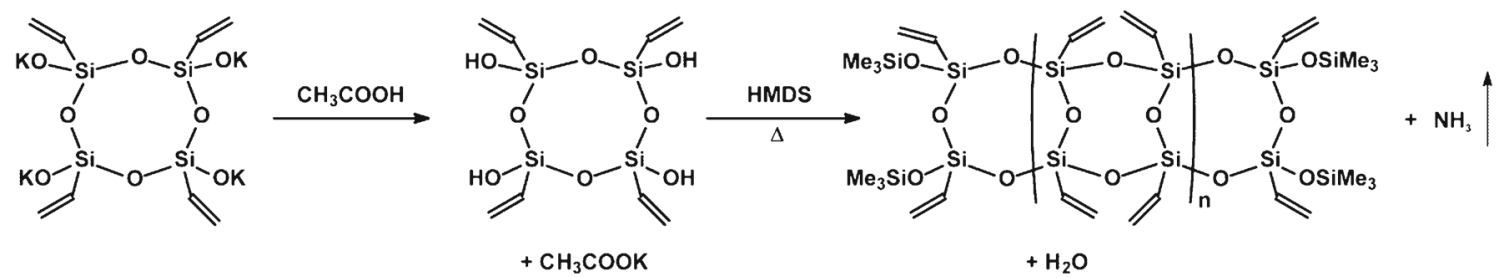

$\mathrm{CH}_{3} \mathrm{COOK}+\mathrm{H}_{2} \mathrm{O} \rightleftharpoons \mathrm{KOH}+\mathrm{CH}_{3} \mathrm{COOH}$

Scheme 2 Formation of basic species in the course of in situ-polycondensation of $[\mathrm{ViSi}(\mathrm{OH}) \mathrm{O}]_{4}$ 


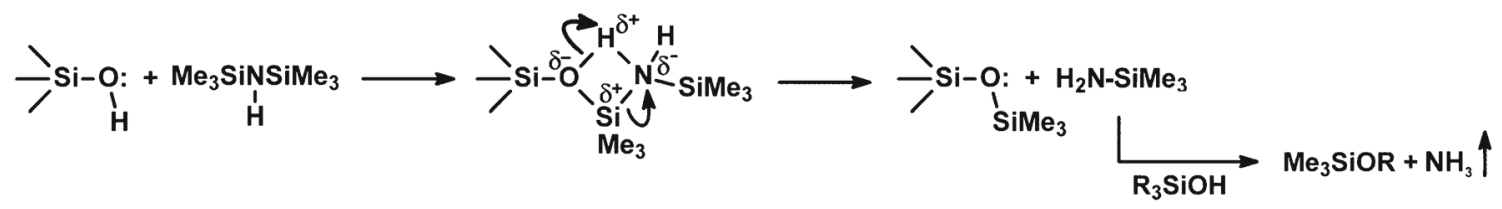

Scheme 3 Silylation of silanols with hexamethyldisilazane via formation of a bimolecular four-centered "O...H...N...Si" transition state

due to steric factors and possibly also due to delocalization of the nitrogen lone pair. The silylating effectiveness of HMDS is low and requires forceful conditions and long reaction times. Under anhydrous conditions, silylation by HMDS proceeds via replacement of the active hydrogen in $\mathrm{SiOH}$ by the trimethylsilyl group. Formation of a bimolecular four-centered "O...H...N...Si" transition state (Scheme 3) in the rate determining step is proposed as a result of nucleophilic attack upon the silicon atom [30]. $\mathrm{H}_{2} \mathrm{NSiMe}_{3}$, which is slightly more basic than HMDS, is the source of another trimethylsilyl group and gaseous ammonia is produced as the only by-product in the process. However, HMDS is sensitive to moisture. The hydrolysis results in formation of $\mathrm{H}_{2} \mathrm{NSiMe}_{3}$ and $\mathrm{Me}_{3} \mathrm{SiOH}$ which can then interact to give $\mathrm{Me}_{3} \mathrm{SiOSiMe}_{3}$. Thus water (and alcohols) should be excluded from the reaction mixture.

The most important source of basic species in the reaction mixture is $\mathrm{CH}_{3} \mathrm{COOK}$, formed as the product of neutralization of silanolate with acetic acid (Scheme 2). It dissolves in $\mathrm{H}_{2} \mathrm{O}$, which is formed continuously during the polycondensation of $\mathrm{SiOH}$ groups $\left(\mathrm{MgSO}_{4}\right.$ was added in some experiments to bind $\mathrm{H}_{2} \mathrm{O}$ ). In consequence a strong base $(\mathrm{KOH})$ is generated. It can be a source of silanolate species, either by reaction with silanol chain ends or by scission of siloxane bonds. $\mathrm{KOH}$ thus determines the reaction course, but is not a cause of random cross-linking.

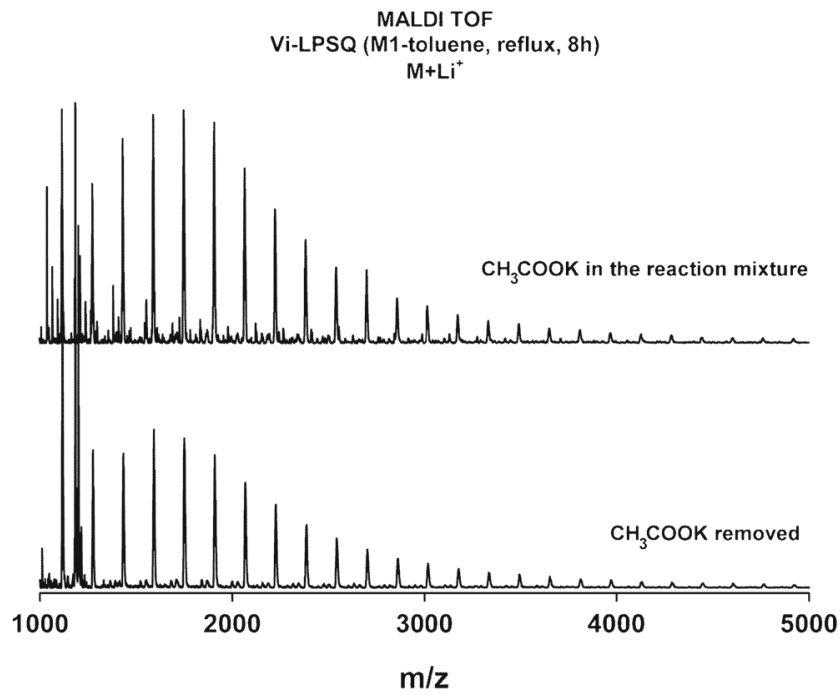

Fig. 2 MALDI-TOF spectra recorded for products obtained according to the procedure $\mathrm{B}$ in the presence of $\mathrm{CH}_{3} \mathrm{COOK}$ (above) and without it (below)
Several modifications of the general procedure were introduced, but the ratio $\left[\mathrm{CH}_{3} \mathrm{COOH}\right] /[$ salt $]$ was adjusted to ensure that the reaction medium was always acidic. In order to generate free monomeric tetrols in the reaction mixture, the salt - potassium tetravinyltetracyclosiloxanolate - was added slowly to a cooled solution of concentrated acetic acid in a chosen solvent (procedure A, Table 1). $\mathrm{CH}_{3} \mathrm{COOK}$ formed in the neutralization step was either filtered off and the solution containing $[\mathrm{ViSi}(\mathrm{OH}) \mathrm{O}]_{4}$ used for the in situ condensation in the presence of HMDS, or the condensation was carried out in a two-phase system in the presence of $\mathrm{CH}_{3} \mathrm{COOK}$. In fact one cannot eliminate partial dissolution of $\mathrm{CH}_{3} \mathrm{COOK}$ and formation of $\mathrm{KOH}$ even at the earliest stages of the reaction, since molecules of $\mathrm{H}_{2} \mathrm{O}$ are present (along with EtOH) in the crystalline structure of $\left\{\left(\mathrm{K}^{+}\right)_{4}\left[\mathrm{ViSi}(\mathrm{O}) \mathrm{O}^{-}\right]_{4}\right\} \mathrm{nL}\left(\mathrm{L}=\mathrm{EtOH}, \mathrm{H}_{2} \mathrm{O}\right)$. In some experiments $\mathrm{CH}_{3} \mathrm{COOH}$ was added drop-wise to a suspension of $\left\{\left(\mathrm{K}^{+}\right)_{4}\left[\mathrm{ViSi}(\mathrm{O}) \mathrm{O}^{-}\right]_{4}\right\} \mathrm{nL}$, (procedure B, Table 1). This did not alter much the structure of the product obtained during the course of the reaction, as indicated by MALDI-TOF MS (Fig. 2) and SEC (RI) (Fig. 3) analyses. However, as one can expect, polycondensation proceeded more effectively in the presence of larger amounts of $\mathrm{CH}_{3} \mathrm{COOK}$.

We have studied (Table 1) the influence of several factors on the course of polycondensation (e.g. the initial concentration of potassium silanolate $[\mathrm{ViSi}(\mathrm{OK}) \mathrm{O}]_{4}$ in the reaction mixture or the molar ratio [HMDS]/[potassium silanolate]).

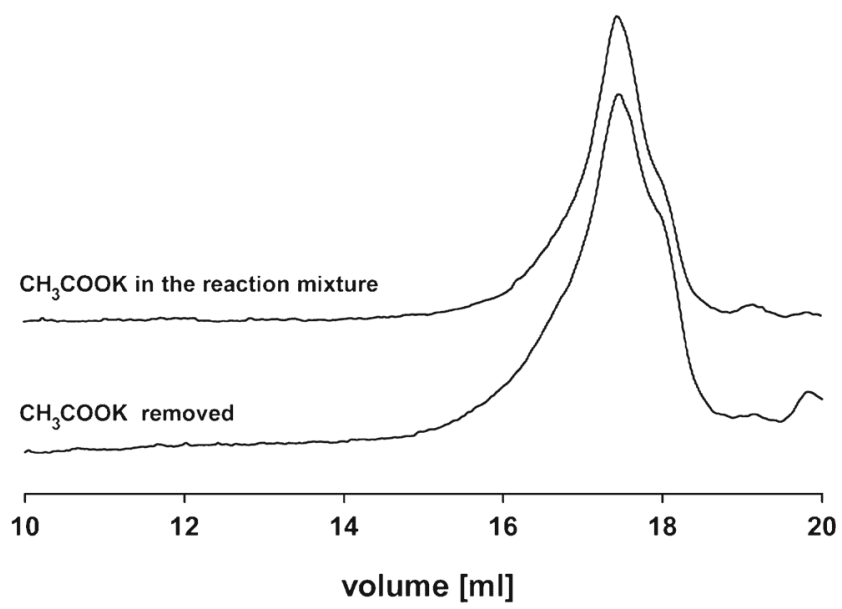

Fig. 3 SEC spectra (RI detection) recorded for products obtained in toluene in the presence of $\mathrm{CH}_{3} \mathrm{COOK}$ (above, Table 1, entry 1-10) and after its removal from the reaction mixture (below, Table 1, entry 1-11) 


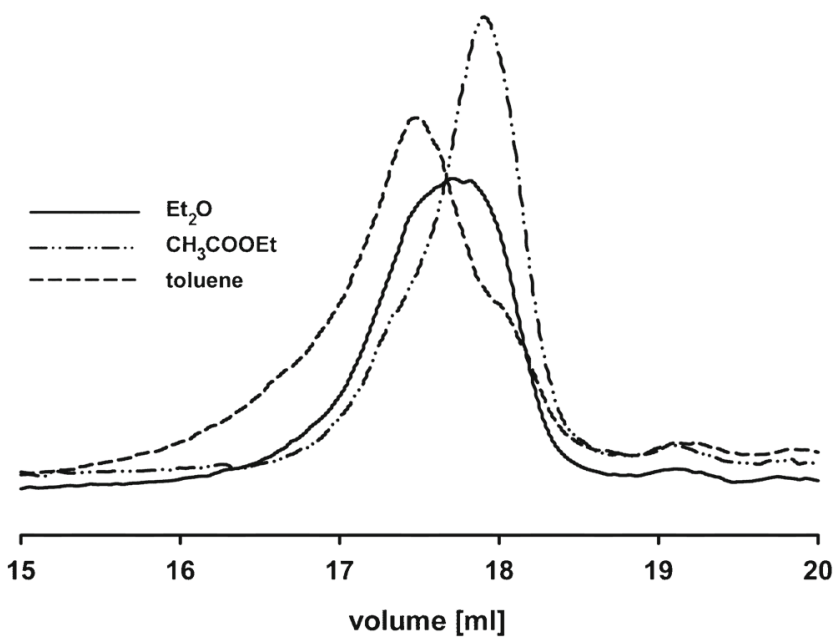

Fig. 4 SEC spectra (RI detection) recorded for products obtained in $\mathrm{Et}_{2} \mathrm{O}, \mathrm{CH}_{3} \mathrm{COOEt}$ and toluene in the presence of $\mathrm{CH}_{3} \mathrm{COOK}$

Absolute molecular mass measurement (MALLS) was impossible for some samples due to their low Mn. SEC (RI) was used for comparison of volumes of elution of the products (Fig. 4). It was found that among all the reaction parameters (the presence of potassium acetate aside) the temperature of the process and the nature of the solvents are of the highest significance.

The catalytic activity of a base can be affected by the reaction medium. Weakly solvating solvents (e.g. toluene) render naked the nucleophile (e.g. silanolate anion) and thus enhance its reactivity. The use of non-polar toluene facilitates formation of high molecular weight Vi-LPSQ oligomers, but as their PDI and Mw (MALLS) increased their volume of elution and Mn (RI) decreases in a rather anomalous way, especially in experiments carried out following procedure B. It was previously reported that the structure of oligomeric Me-LPSQs changed from linear to

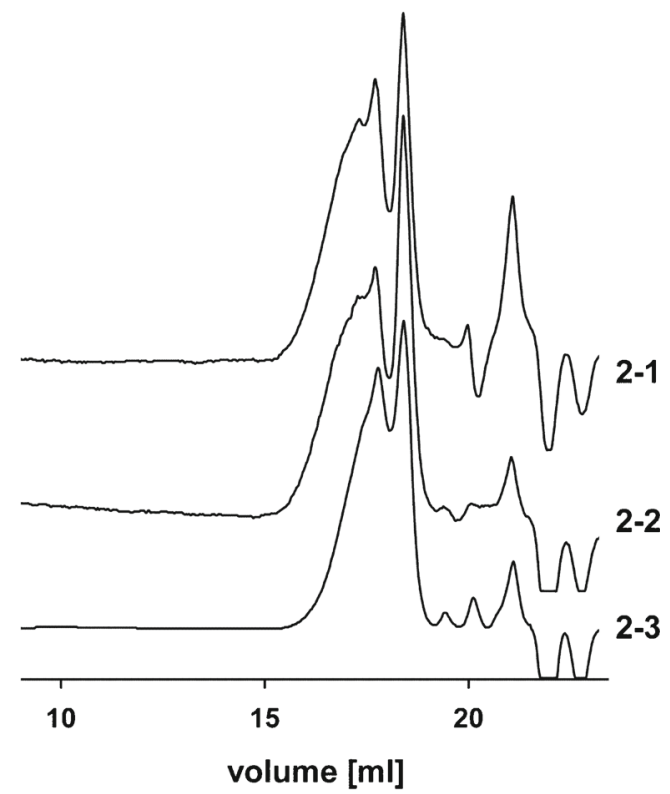

Fig. 5 SEC spectra (RI detection) recorded for products obtained in $\mathrm{Et}_{2} \mathrm{O}(2-1)$ and $\mathrm{CH}_{3} \mathrm{COOEt}(2-2,2-3)$ in the presence of $\mathrm{Et}_{3} \mathrm{~N}$ (Table 2)

branched species, as their molecular weight increased [25]. It seems to be the case for Vi-LPSQs obtained in toluene.

It appears that the solvent should preferably dissolve $\mathrm{CH}_{3} \mathrm{COOK}$, but only to a very small extent. $\mathrm{Et}_{2} \mathrm{O}$ would be a good candidate, but its high volatility limited the temperature range of the reaction. Polaraprotic ethyl acetate was found to be the best solvent for in situ condensation of 2,4,6,8-tetrahydroxy-2,4,6,8tetravinyl-cyclotetrasiloxanes especially conforming to procedure A. It does not cause excessive solvation of potassium ions but is able to take part in hydrogen bonding with silanols. Completely non-polar solvents, such as hexane, did not promote polycondensation of $[\mathrm{ViSi}(\mathrm{OH}) \mathrm{O}]_{4}$.

Table 2 Reaction parameters and characteristics of the products obtained by in situ condensation of tetravinylsiloxanetetraol carried out in the presence of $\mathrm{Et}_{3} \mathrm{~N}$ and HMDS

\begin{tabular}{|c|c|c|c|c|c|c|c|c|c|c|c|}
\hline Entry & $\mathrm{a}_{0}\left[\mathrm{~mol} / \mathrm{dm}^{3}\right]$ & $\mathrm{b}$ & $\mathrm{c}$ & $\mathrm{d}$ & Solvent & $\mathrm{T}_{1}\left[{ }^{\circ} \mathrm{C}\right]$ & $\mathrm{t}_{1}[\mathrm{~h}]$ & $\mathrm{T}_{2}\left[{ }^{\circ} \mathrm{C}\right]$ & $\mathrm{t}_{2}[\mathrm{~h}]$ & $\mathrm{Mn}$ & $\mathrm{PDI}_{1}$ \\
\hline \multirow[t]{2}{*}{$2-1$} & 0.28 & 1.32 & 0.004 & 0.004 & $\mathrm{Et}_{2} \mathrm{O}$ & $\mathrm{RT}$ & 18 & 35 & 48 & 2500 & 1.4 \\
\hline & & & & & & & & & & 900 & 1.1 \\
\hline \multirow[t]{2}{*}{$2-2$} & 0.28 & 1.32 & 0.021 & 0.021 & $\mathrm{CH}_{3} \mathrm{COOEt}$ & $\mathrm{RT}$ & 18 & 78 & 48 & 2700 & 1.4 \\
\hline & & & & & & & & & & 900 & 1.1 \\
\hline \multirow[t]{2}{*}{$2-3$} & 0.05 & 4.10 & 0.040 & 0.400 & $\mathrm{CH}_{3} \mathrm{COOEt}$ & $\mathrm{RT}$ & 170 & 78 & $7 \mathrm{~h}$ & 2000 & 1.3 \\
\hline & & & & & & & & & & 700 & 1.1 \\
\hline
\end{tabular}

\footnotetext{
$\mathrm{a}_{0}$ - initial concentration of potassium silanolate $[\mathrm{ViSi}(\mathrm{OK}) \mathrm{O}]_{4}$ in the reaction mixture

$\mathrm{b}$ - molar ratio $\left[\mathrm{CH}_{3} \mathrm{COOH}\right] /[$ potassium silanolate $]$

$\mathrm{c}$ - molar ratio $\left[\mathrm{Et}_{3} \mathrm{~N} /[\right.$ potassium silanolate]

$\mathrm{d}$ - molar ratio [HMDS]/[potassium silanolate]

$\mathrm{T}$ - temperature

$\mathrm{t}-$ reaction time

$\mathrm{Mn}, \mathrm{PDI}_{1}-$ molecular mass and polydispersity derived from SEC-RI
} 
Scheme 4 Oligomeric species detected during condensation of $[\mathrm{ViSi}(\mathrm{OH}) \mathrm{O}]_{4}$ in the presence of HMDS

a
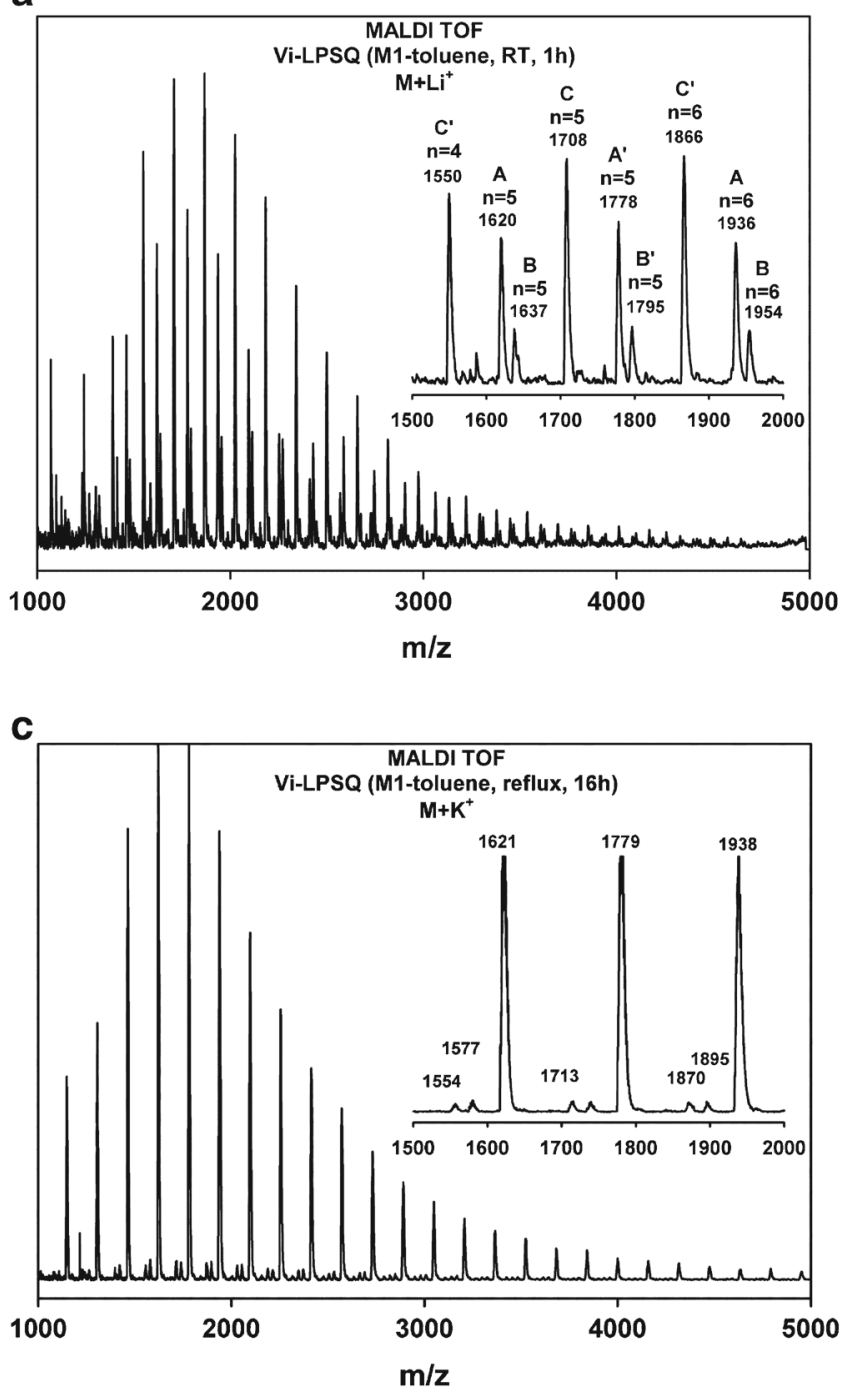<smiles>C=C[Si]1(O)O[Si]2(C=C)O[Si]3(C=C)O[Si]4(C=C)O[Si](C=C)(O1)O[Si](C=C)(O3)O[Si]1(C=C)O[Si](C=C)(O[Si](C=C)(O2)O4)O1</smiles>

$A^{\prime}: 1.5 n$

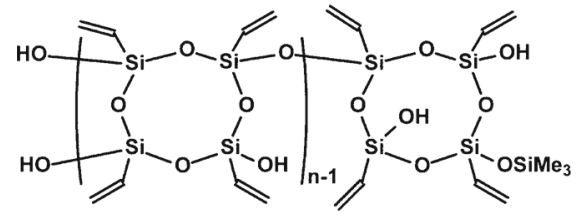

C: $\mathbf{n}$<smiles>C=C[Si]1(O)O[Si]2(O)O[Si]3(C=C)O[Si](C=C)(O1)O[Si](O)(C=C)O[Si]1(C=C)O[Si](O)(C=C)O[Si](C=C)(O2)C(O)(O)[Si](C=C)(O1)O3</smiles>

B: $\mathbf{n}$

B': $1.5 n$

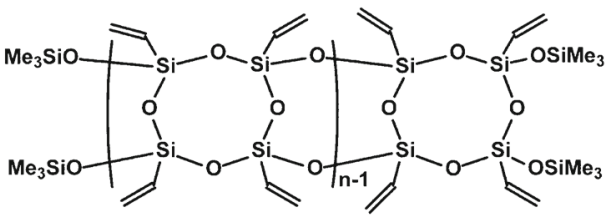

D: $\mathbf{n}$

$D^{\prime}: 1.5 n$ b

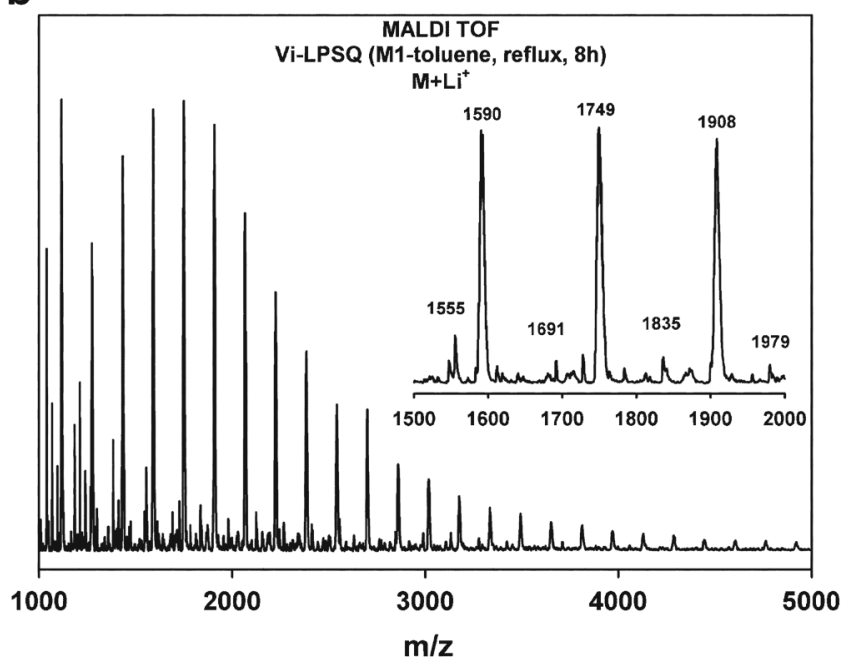

d

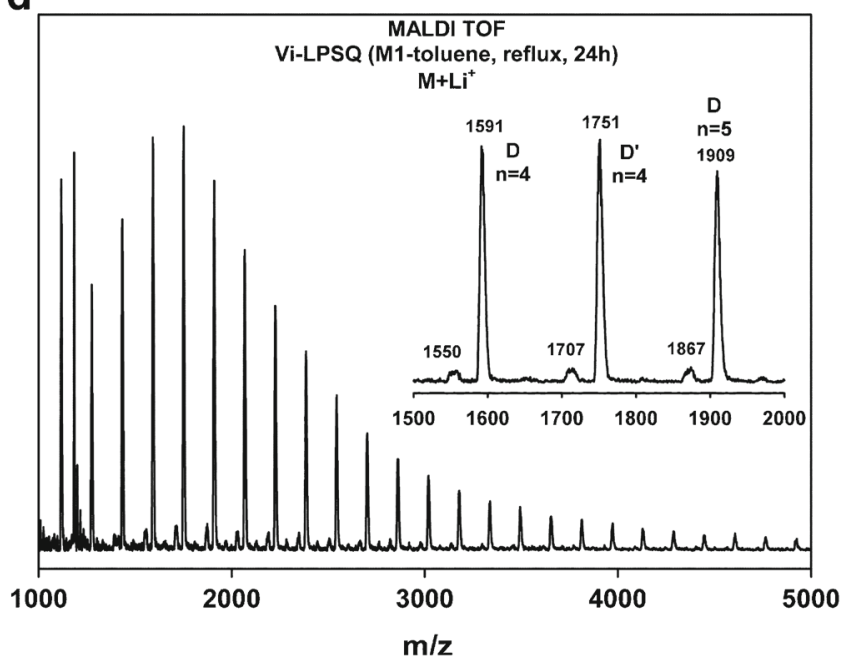

Fig. 6 Composition of oligomeric species formed during in situ condensation of $[\mathrm{ViSi}(\mathrm{OH}) \mathrm{O}]_{4}$ in toluene (a) after 1 hour at room temperature, (b) after 8 hours at $110^{\circ} \mathrm{C},(\mathbf{c})$ after 16 hours at $110^{\circ} \mathrm{C}$, (d) after 24 hours at $110^{\circ} \mathrm{C}$ 
a

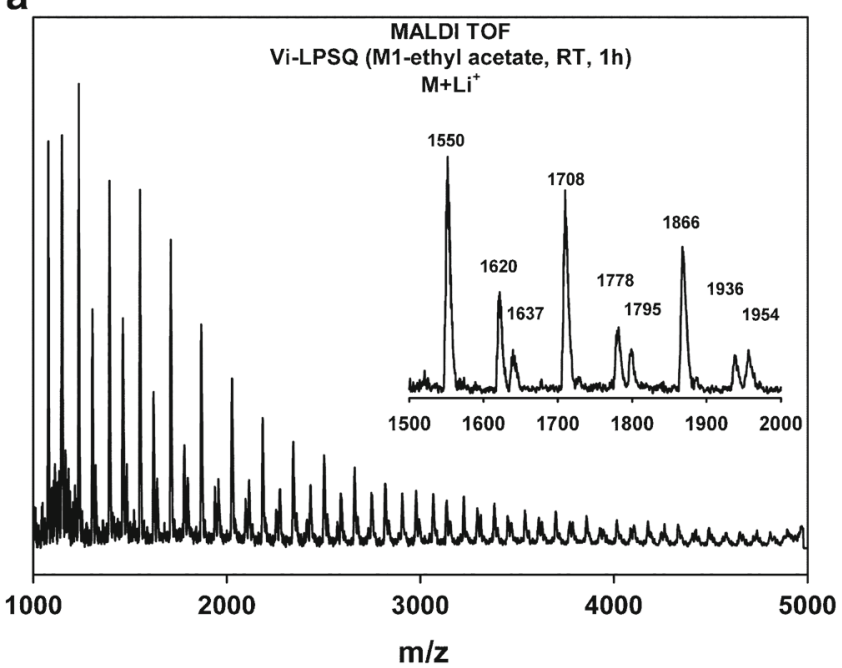

b

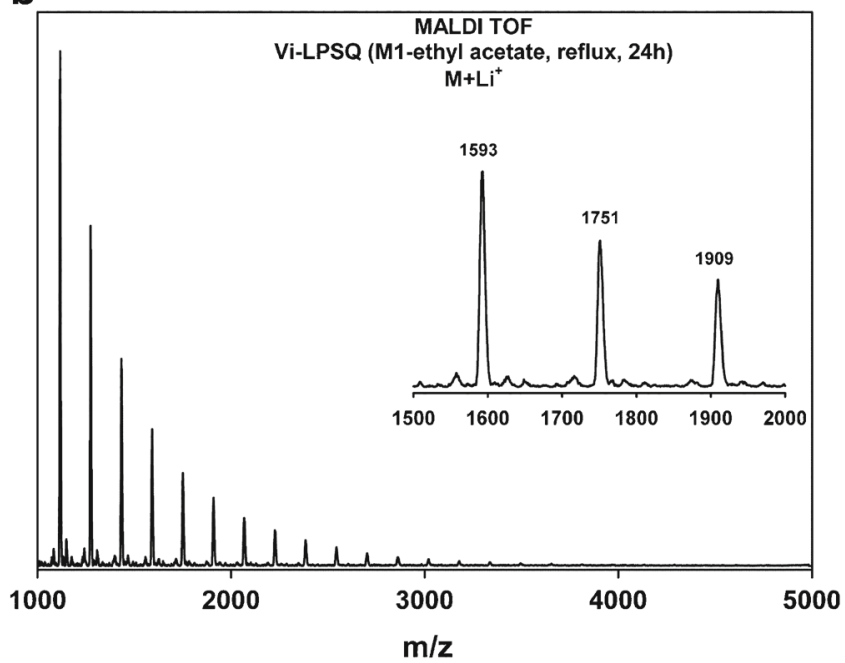

Fig. 7 Composition of oligomeric species formed during in situ condensation of $[\mathrm{ViSi}(\mathrm{OH}) \mathrm{O}]_{4}$ in $\mathrm{CH}_{3} \mathrm{COOEt}(\mathbf{a})$ after 1 hour at room temperature, (b) after 24 hours at $110{ }^{\circ} \mathrm{C}$

Interactions with highly solvating and/or proton donating species reduce the negative charge at a nucleophilic moiety and weaken its nucleophilicity [31]. Redistribution reactions in polysiloxanes are thus usually slowed down in the presence of strong cation solvating agents [32]. However, in the process studied here, the polar and/or proton donating solvents (EtOH, DMF, $\mathrm{CH}_{3} \mathrm{CN}$ ) tend to promote branching and cross-linking with formation of insoluble materials (Table 1). This can be explained by excessive hydrogen bonding between silanol groups and solvent molecules. We were not able to determine whether redistribution took place.

The concentration of the reaction mixture was found to be of importance. The experiments with higher concentrations of potassium silanolate resulted in products with larger discrepancies between Mn (RI) and Mw (MALLS). The molar ratio [HMDS]/[potassium silanolate] had no clear influence on the structure of the Vi-LPSQs although it can be surmised that decreasing the amount of HMDS below a certain limit would give more branched oligomers and polymers. It was also found that the reaction proceeds better without any supplementary catalyst added. Introduction of nucleophilic species, such as $\mathrm{Et}_{3} \mathrm{~N}$ (Table 2, procedure $\mathrm{A}, \mathrm{Et}_{3} \mathrm{~N}$ added after filtration of $\mathrm{CH}_{3} \mathrm{COOK}$ ), increased the rate of polycondensation, which resulted in formation of polymers of multimodal structure (Fig. 5).

\subsection{MALDI-TOF Analysis}

With the right choice of experimental conditions, MALDITOF MS can be a useful method for determination of the details of the structure of polymeric chains of LPSQ materials. For example, MALDI-TOF spectrometry was used to determine the number of uncondensed $\mathrm{SiOH}$ groups in Me-LPSQs obtained by polycondensation of cis-transcis $[\mathrm{MeSi}(\mathrm{OH}) \mathrm{O}]_{4}$ [13]. According to the reported data, linear chains of Me-LPSQs have two uncondensed sites (cyclolinear points) which spoil the doublechain structure.

We have obtained satisfactory MALDI-TOF results on the structure of the products formed during the in-situ polycondensation of $[\mathrm{ViSi}(\mathrm{OH}) \mathrm{O}]_{4}$. Silanol-terminated ViLPSQ oligomers (A, B, Scheme 4, Fig. 6a) are formed in the first stages of condensation in toluene. They undergo silylation with HMDS to give monosilylated species C, and finally D structures at higher temperatures (Scheme 4, Fig. 6b-d). Silylation in $\mathrm{CH}_{3} \mathrm{COOEt}$ proceeds effectively and after 1 hour at room temperature silanol-terminated species were detected in a smaller amount than in toluene (Fig. 7a). The degree of condensation varied depending on the type of solvent, but the pattern of oligomeric species detected by MALDI was the same (Figs. 7 and 8).

Along with the expected sequence of oligomers $(n=2$, 3, 4 etc.), a supplementary series of congeneric species (A', B', C', D') with $\mathrm{n}=1.5,2.5,3.5$ etc., was formed due to base-catalyzed siloxane bond redistribution. The process, under the experimental conditions studied, can be explained in terms of multifunctional interactions of siloxane bonds with silanolate moieties leading to chain redistribution. The species in the reaction mixture consist of tetrameric siloxane rings. The lone pairs of the oxygen atoms in the siloxane bonds of the rings and exocyclic oxygen atoms (e.g. in $\mathrm{Me}_{3} \mathrm{SiO}$ end groups) can be involved in the bonding of the alkali ions, acting as electron donors as they do in crown ethers [33]. Similar chain redistribution and cyclization processes due to the interaction of siloxane bonds and silanolate groups, giving assistance to the cleavage 

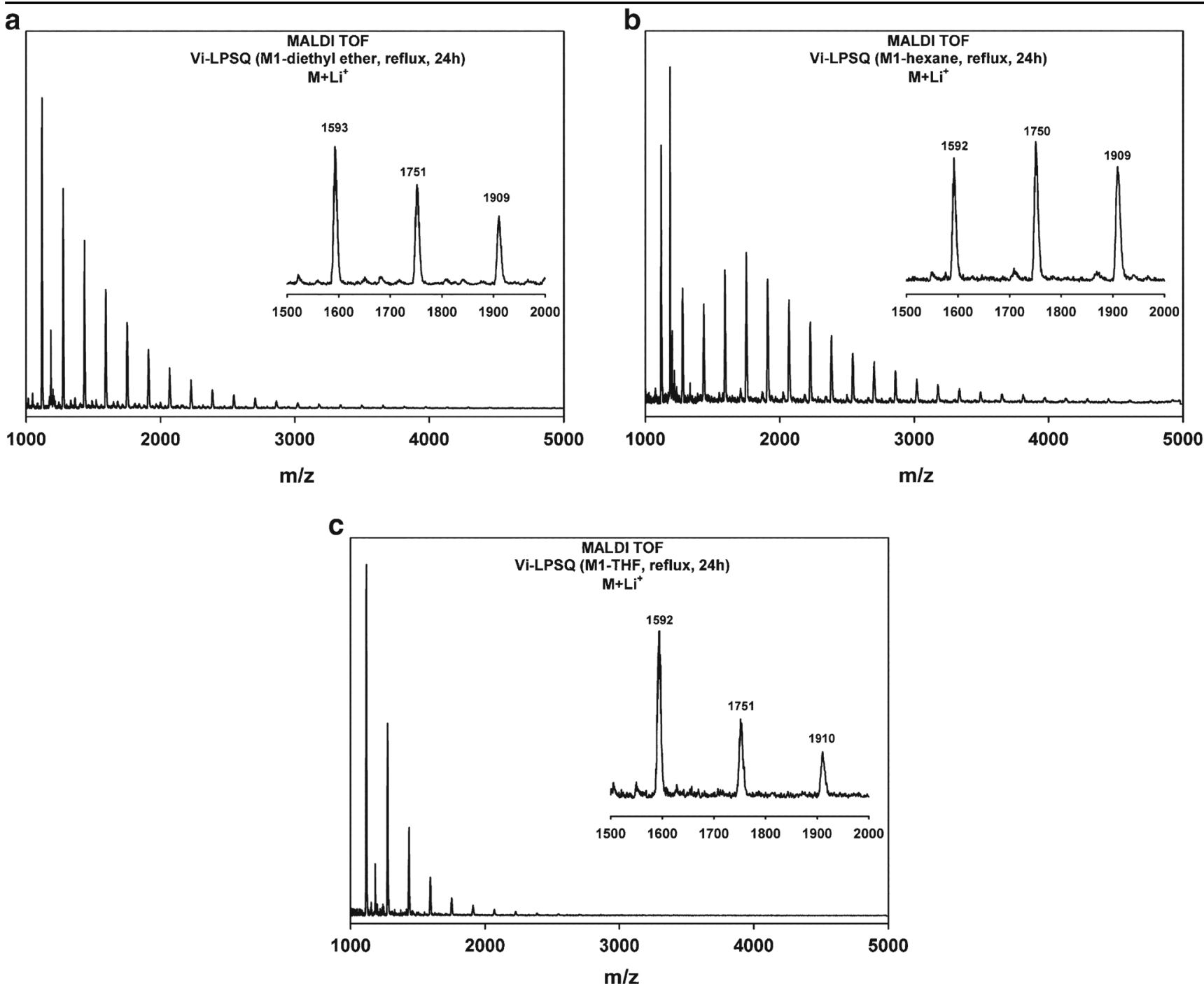

Fig. 8 Composition of oligomeric species formed during in situ condensation of [ $\mathrm{ViSi}(\mathrm{OH}) \mathrm{O}_{4}$ after 24 hours of reflux in $\mathrm{Et}_{2} \mathrm{O}(\mathbf{a})$, hexane (b) and tetrahydrofuran $(\mathbf{c})$

of siloxane bonds, were observed during anionic polymerization of siloxanes [32] and disproportionation of $\alpha, \omega$ dihydroxy(polydimethylsiloxanes) in the presence of alkali metal alkoxides or $\mathrm{NaOH}$ [34]. A rapid exchange between the protons of $\mathrm{SiOH}$ groups of organosilanols and cations of alkali-metal organosilanolates along with disproportionation of siloxane bonds was observed during copolymerization of $\alpha, \omega$-dihydroxy(oligodimethylsiloxane) with 1,3,5,7tetramethyl-1,3,5,7-tetravinylcyclotetrasiloxane [35]. Disproportionation of $\alpha, \omega$-(oligomethylsiloxanols) and redistribution of siloxane bonds occurred in the presence of superbases [31]. Simultaneous cleavage of two siloxane bonds was also proposed to explain the formation of specific stereoisomers during acidic hydrolysis of $\left(\mathrm{K}^{+}\right)_{4}\left[\mathrm{MeSi}(\mathrm{O}) \mathrm{O}^{-}\right]_{4}$ [28]. Such reactivity enhancement and disproportionation of siloxane bonds can be explained by a mechanism combining elements of bimolecular nucleophilic substitution and elimination-addition with formation of pentacoordinate silicon transition state/intermediate [31, $32,34]$.

However, not only siloxane bonds close to the terminal $\mathrm{SiOH}$ groups seem to be affected. Siloxane bonds in double-strand chains can be also broken in the presence of potassium ions. Simultaneous disruption of siloxane bonds at the parallel threads of silsesquioxane ladders can be explained by the cleavage of several siloxane bonds weakened by interactions with potassium ions, and thus more prone to nucleophilic attack.

\subsection{Structural Analysis and Physiochemical Properties}

The Vi-LPSQs were characterized by NMR, SEC with RI and MALLS (for samples of high molecular mass) detection, X-ray diffraction, DSC and TGA of liquid and solid materials. For comparison of structure and properties, Vi-functionalized silsesquioxanes were also obtained by 
Fig. $9{ }^{29} \mathrm{Si} \mathrm{NMR}$ of vinyl-polysilsesquioxanes (liquid state spectrum of oligomeric Vi-LPSQs in $\mathrm{CDCl}_{3}$ (a)) and CP MAS spectra of polymeric Vi-LPSQs (SCP) (b) and cross-linked Vi-PSQ (c)

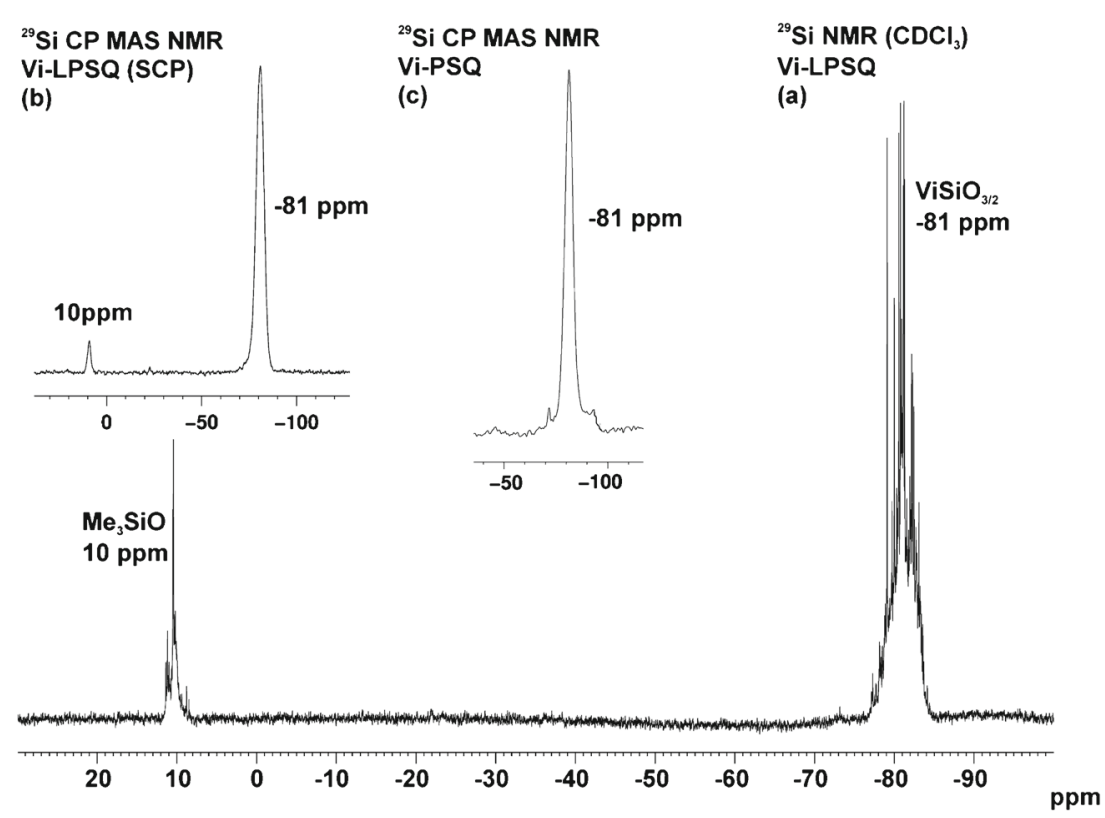

other preparative procedures. Synthesis of Vi-LPSQs by stepwise coupling polymerization resulted in a soluble product of high molecular mass. Hydrolytic condensation of $\mathrm{ViSi}(\mathrm{OEt})_{3}$ catalyzed with $\mathrm{K}_{2} \mathrm{CO}_{3}$ gave insoluble, crosslinked condensed solids (Vi-PSQ). ${ }^{29} \mathrm{Si}$ NMR analysis can be an indicator of high degree of regularity of the polymer

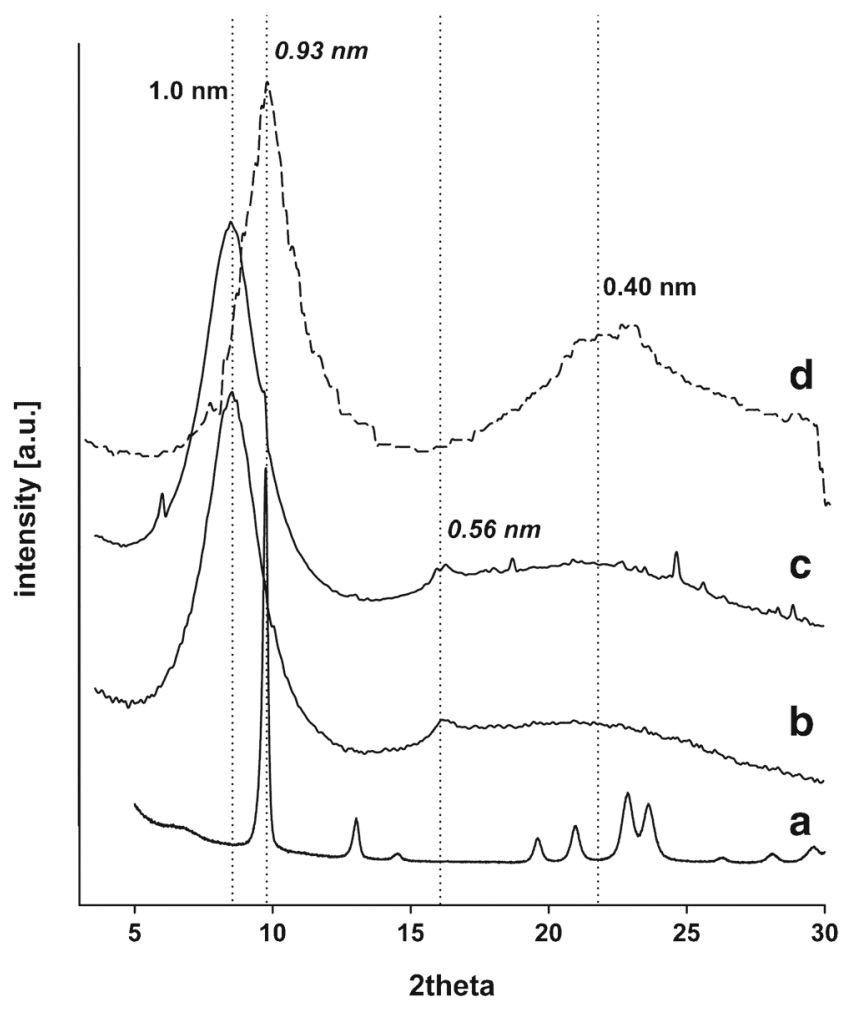

Fig. 10 WAXS diffraction patterns recorded for model $\mathrm{T}_{8} \mathrm{Vi}(\mathbf{a})$, ViLPSQs obtained in $\mathrm{CH}_{3} \mathrm{COOEt}(\mathbf{b})$, Vi-LPSQs obtained in toluene (c), Vi-LPSQs (SPC) (d) structure [7]. It is generally accepted that the narrower the peaks corresponding to $\mathrm{RSiO}_{3 / 2}$ the less the structural defects in the architecture of the polymer backbone. This is not always the case, since peak widths at half-height for cross-linked sample of Vi-PSQ and highly regular Vi-LPSQs (SCP) in their ${ }^{29} \mathrm{Si}$ CP MAS NMR spectra are almost the same (Fig. 9 insert $\mathbf{c}$ and $\mathbf{b}$ respectively). The ladder siloxanes obtained via in situ polycondensation of $[\mathrm{ViSi}(\mathrm{OH}) \mathrm{O}]_{4}$ are a mixture of stereoisomers of different chain length, and thus resonances corresponding to $\mathrm{ViSiO}_{3 / 2}$ are rather broad and composed of several components (Fig. 9a).

WAXS confirmed the formation of ordered structures in linear Vi-LPSQs (Fig. 10b-c), comparable to that of highly regular Vi-LPSQs (SPC) prepared via supramolecular template polymerization (Fig. 10d). A slight difference in the

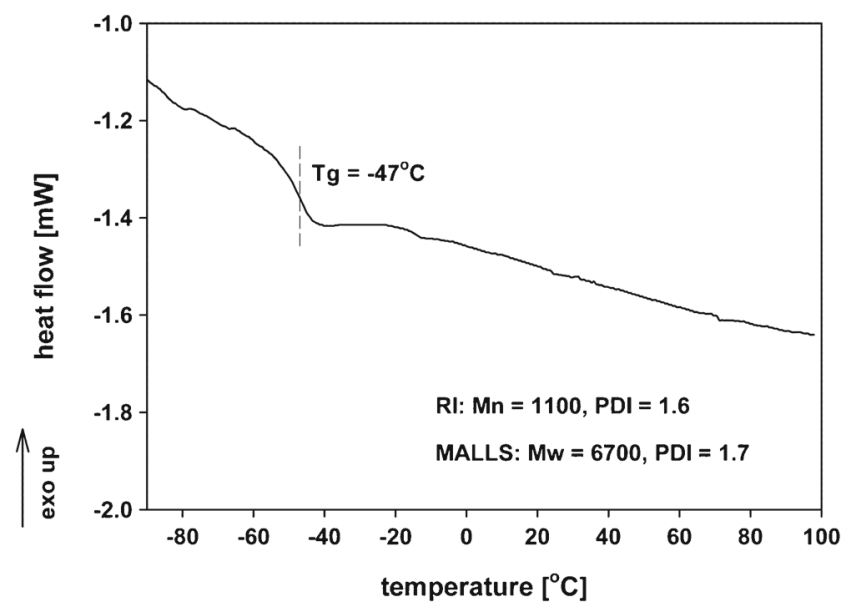

Fig. 11 DSC trace of a Vi-LPSQs prepared in toluene 


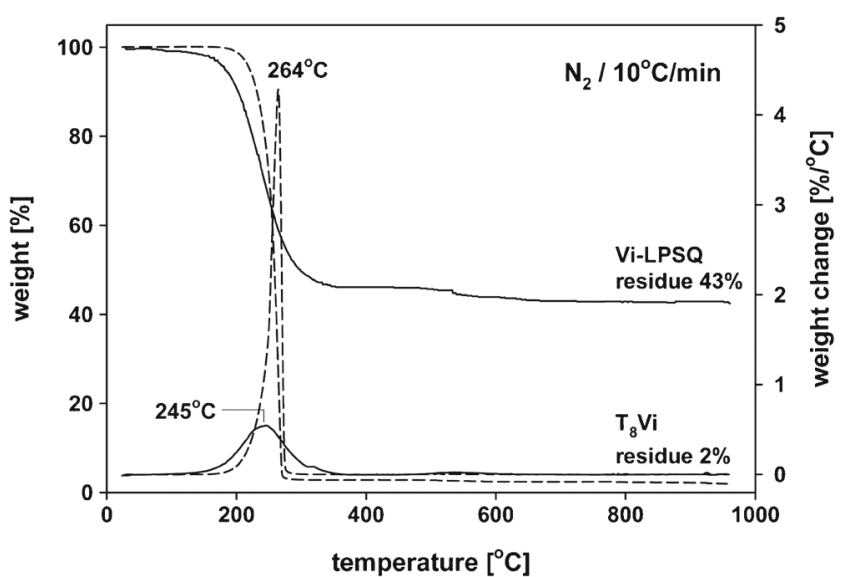

Fig. 12 Comparison of thermal stability of $\mathrm{T}_{8} \mathrm{Vi}$ and Vi-LPSQs $\left(\mathrm{Mn}_{(\mathrm{RI})}=1100, \mathrm{PDI}=1.6, \mathrm{Mw}_{(\mathrm{MALLS})}=6700\right)$

position of the major diffraction peak can be explained in terms of different arrangement of silsesquioxane frameworks and the disposition of vinyl groups [cis-syndiotactic conformation in Vi-LPSQs (SPC) and random in Vi-LPSQs obtained by in situ condensation]. This suggestion is supported by the fact that the cross-linked and insoluble Vi-PSQ obtained by polycondensation of $\mathrm{ViSi}(\mathrm{OEt})_{3}$ (with ordered structures confined in the network) exhibits similar diffraction peaks at $\mathrm{d}_{1}=0.71 \mathrm{~nm}$ and $\mathrm{d}_{2}=0.29 \mathrm{~nm}$. The formation of polyhedral species can also be examined. Octahedral silsesquioxane $\left(\mathrm{T}_{8} \mathrm{Vi}\right)$ was not obtained during the synthesis (Fig. 10, trace a shows WAXS diffraction pattern of the original compound). But if the condensation was carried out in toluene the linear product was admixed with a small amount of a crystalline material that could not be isolated from the mixture of oligomers. The data obtained with MALDI-TOF in the low molecular weight region (Supporting information, Figs. 1-6SI), can suggest that incompletely

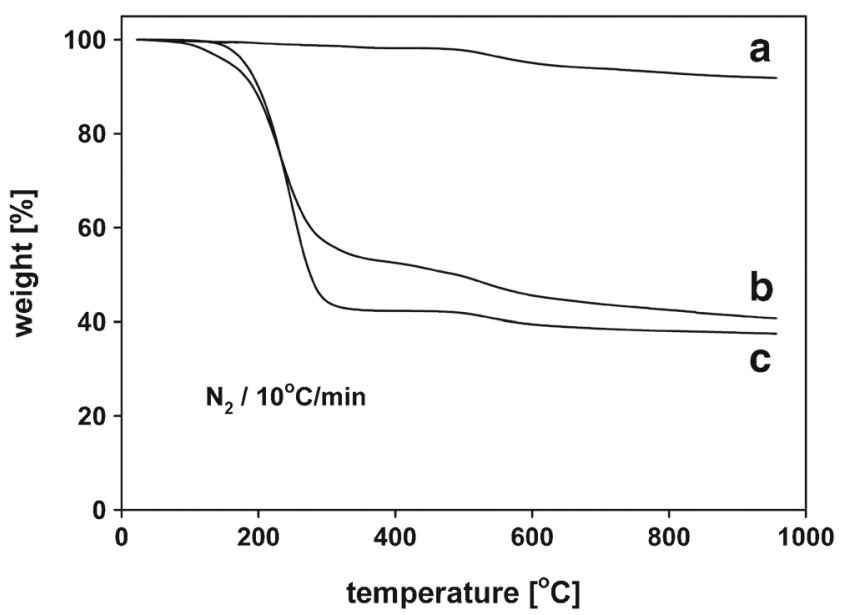

Fig. 13 Comparison of thermal stability of cross-linked Vi-PSQ (a) and Vi-LPSQs prepared in $\mathrm{CH}_{3} \mathrm{COOEt}(\mathbf{b})$ and THF (c) condensed but silylated polyhedral species $\mathrm{T}_{10} \mathrm{Vi}\left(\mathrm{SiMe}_{3}\right)_{2}$ and $\mathrm{T}_{12} \mathrm{Vi}\left(\mathrm{SiMe}_{3}\right)_{2}$ (Supporting information, Scheme 1-SI) may be formed during the reaction. However, the same MALDI-TOF patterns were found in samples prepared in $\mathrm{CH}_{3} \mathrm{COOEt}$, which did not show admixture of crystalline species in their WAXS diffraction patterns. Other molecules of $\mathrm{m} / \mathrm{z} 1275,1433$ and 1591 could be also ascribed to the series of incompletely condensed silylated species, but they probably should be attributed to linear oligomers. This is supported by the fact that they form a coherent sequence with oligomers of higher molecular weight, whereas condensed polyhedral molecules would give peaks at completely different $\mathrm{m} / \mathrm{z}$. Moreover, the shape of SEC traces obtained for Vi-LPSQs resembles those of polymers with a statistical distribution of chains. A sequence of polyhedral molecules would give a set of separate sharp peaks.

The obtained materials are viscous liquids and the only phase transition they exhibit is devitrification at low temperatures (Fig. 11). They are thermally stable and decompose to leave about $40 \%$ residue in $\mathrm{N}_{2}$ (Figs. 12 and 13). Comparing TGA traces of $\mathrm{T}_{8} \mathrm{Vi}$ and Vi-LPSQs (Fig. 12) one can notice a significant difference. $\mathrm{T}_{8} \mathrm{Vi}$ sublimes quite rapidly under the analysis conditions at $260-265{ }^{\circ} \mathrm{C}$ to leave $2 \%$ residue. The weight of a sample of Vi-LPSQs decreases rapidly in the temperature range $200-300{ }^{\circ} \mathrm{C}$, which suggests evaporation of the shortest and volatile oligomers. At about $500{ }^{\circ} \mathrm{C}$ one can notice a small change of weight that can be related to polymerization of vinyl groups in the less volatile material. The same process was reported in the literature for poly(vinylsilsesquioxanes) [36] as well as for Vi-PSQ and Vi-LPSQs synthesized in $\mathrm{CH}_{3} \mathrm{COOEt}$ and THF (Fig. 13a-c). The sample prepared in THF contains mostly oligomeric species (MALDI-TOF analysis, Fig. 8c) and the corresponding weight decrease due to their volatilization is more pronounced.

\section{Conclusions}

We have found that soluble oligovinylsilsesquioxanes can be obtained via condensation of cyclic organosiloxane tetraols obtained in situ from their alkali metal cyclosiloxolate precursors. The use of a silanol group blocking agent - hexamethyldisilazane - is crucial for the formation of linear and bench-stable Vi-LPSQs by condensation of $[\mathrm{ViSi}(\mathrm{OH}) \mathrm{O}]_{4}$. The ladder structure of the materials was confirmed by analytical methods.

We have studied the influence of reaction conditions on the structure of LPSQs. It was found that the reaction medium can induce structural changes in the LPSQ product. In some solvents incompletely condensed linear oligomers were formed at the initial stage of the reaction, 
to be subsequently silylated by HMDS. The process of condensation is catalyzed by $\mathrm{K}^{+}$ions present in the reaction mixture. However, the potassium derivatives cause at the same time redistribution of siloxane bonds and formation of congeneric series of linear oligomers.

Acknowledgments This work was supported by National Science Centre grant DEC-2011/03/B/ST5/02672 'Studies on preparation and structurization of new hybrid materials". The authors wish to thank Dr. J. David Smith (University of Sussex) who assisted in the proofreading of the manuscript, Mgr Beata Wiktorska and Mgr Marcin Florczak (CMMS, PAS) for SEC(RI/MALLS) and MALDI-TOF analyses and Dr. Bartosz Handke (AGH) for WAXS measurements of liquid Vi-LPSQs.

\section{References}

1. Choi SS, Lee AS, Lee HS, Jeon HY, Baek KY, Choi DH, Hwang SS (2011) Synthesis and characterization of UV-curable ladder-like polysilsesquioxane. J Polym Sci Part A: Polym Chem 49:5012-5018

2. Brown JF, Vogt LH, Katchman A, Eustance JW, Kaiser KM, Krantz KW (1960) Double chain polymers of phenylsilsesquioxane. J Am Chem Soc 82:6194-6195

3. Brook MA (2000) Silicon in organic, organometallic, and polymer chemistry. John Wiley, New York, p 309

4. Pielichowski K, Njuguna J, Janowski B, Pielichowski J (2006) Polyhedral oligomeric silsesquioxanes (POSS)-containing nanohybrid polymers in supramolecular polymers polymeric betains oligomers. Adv Polym Sci 201:225-296

5. Leśniak E, Polimery (2001) Silsesquioxanes. Part II. Polysilsesquioxanes. 46:582-589

6. Unno M, Suto A, Matsumoto T (2013) Laddersiloxanes silsesquioxanes with defined ladder structure. Russ Chem Rev 82:289-302

7. Zhang ZX, Hao J, Xie P, Zhang X, Han Ch C, Zhang R (2008) A well-defined ladder polyphenylsilsesquioxane (Ph-LPSQ) synthesized via a new three-step approach: Monomer self-organizationlyophilization-surface-confined polycondensation. Chem Mater 20:1322-1330

8. Ren Z, Xie P, Jiang S, Yan S, Zhang R (2010) Study of the supramolecular architecture-directed synthesis of a well-defined triple-chain ladder polyphenylsiloxane. Macromol 43:2130-2136

9. Chen Z, Li Z, Guo H, Zhang J, Ren Z, Yan S, Xie P, Zhang R (2012) Supramolecular Template-Directed Synthesis of Soluble Quadruple-Chain Ladder Polyphenylsiloxane (Ph-QCLP) with High Molecular Weight. Chem Mater 24:1968-1973

10. Jia XW, Rong MZ, Zhang MQ, Ye XJ (2010) A facile approach for preparing polymethylphenylsilsesquioxane with well-defined ladder structure via nonhydrolytic condensation. Chem Lett 39:10101012

11. Seki H, Kajiwara T, Abe Y, Gunji T (2010) Synthesis and structure of ladder polymethylsilsesquioxanes from sila-functionalized cyclotetrasiloxanes. J Organomet Chem 695:1363-1369

12. Andrianov KA, Tverdokhlebova II, Makarova NN, Mamayeva II, Chekalov AK, Men'shov VM, Pavlova S-SA (1978) On the polycondensation products of cis-(1,3,5,7-tetrahydroxy)-1,3,5,7tetraphenylcyclo-tetrasiloxane. Polym Sci U.S.S.R. 20:425-431

13. Lee HS, Choi SS, Baek KY, Hong SM, Lee EC, Lee JC, Hwang SS (2012) Synthesis and structure characterization of ladder-like polymethylsilsesquioxane (PMSQ) by isolation of stereoisomer. Eur Polym J 48:1073-1081
14. Seki H, Abe N, Abe Y, Gunji T (2011) Synthesis and structure of syn,anti,syn-pentacyclic ladder oligomethylsilsesquioxane. Chem Lett 40:722-723

15. Unno M, Suto A, Takada K, Matsumoto H (2000) Synthesis of ladder and cage silsesquioxanes from 1,2,3,4tetrahydroxycyclotetrasiloxane. Bull Chem Soc Jpn 73:215-220

16. Unno M, Suto A, Matsumoto H (2002) Pentacyclic laddersiloxane. J Am Chem Soc 124:1574-1575

17. Unno M, Tanaka R, Tanaka S, Takeuchi T, Kyushin S, Matsumoto H (2005) Oligocyclic ladder polysiloxanes: Alternative synthesis by oxidation. Organometallics 24:765-768

18. Unno M, Matsumoto T, Matsumoto H (2012) Nonacyclic ladder silsesquioxanes and spectral features of ladder polysilsesquioxanes. Int J Polym Sci. Article ID 723892

19. Chang S, Matsumoto T, Matsumoto H, Unno M (2010) Synthesis and characterization of heptacyclic laddersiloxanes and ladder polysilsesquioxane. Appl Organometal Chem 24:241-246

20. Abe Y, Suyama K, Gunji T (2006) Synthesis and structure of cis-trans-cis-1,3,5,7-tetraisocyanato-1,3,5,7-tetramethylcyclotetrasiloxane. Chem Lett 35:114-115

21. Suyama K, Gunji T, Arimitsu K, Abe Y (2006) Synthesis and structure of ladder oligosilsesquioxanes: Tricyclic ladder oligomethylsilsesquioxanes. Organometallics 25:55875593

22. Krishnan PSG, He C, Shang CTS (2004) J Polym Sci Part A: Polym Chem 16:4036-4046

23. Armarego WLF, Chai ChLL (2003) Purification of laboratory chemicals, 5th edn. Elsevier Science

24. Sparks BJ, Kuchera TJ, Jungman MJ, Richardson AD, Savin DA, Hait S, Lichtenhan J, Striegel MF, Patton DL (2012) Cyclic tetravinylsiloxanetetraols as hybrid inorganic-organic thiol-ene networks. J Mater Chem 22:3817-3824

25. Lee HS, Choi SS, Baek KY, Lee ECh, Hong SM, Lee JCh, Hwang SS (2012) Structural analysis of high molecular weight PMSQs and their related properties for interlayer dielectric (ILD) application. Macromol Res 20:1131-1136

26. Shchegolikhina OI, Pozdnyakova YuA, Chetverikov AA, Peregudov AS, Buzin MI, Matukhina EV (2007) cisTetra[(organo)(trimethylsiloxy)]cyclotetrasiloxanes: synthesis and mesomorphic properties. Russ Chem Bull, Int Ed 56:83-90

27. Shchegolikhina OI, Pozdnyakova YuA, Molodtsova YuA, Korkin SD, Bukalov SS, Leites LA, Lyssenko KA, Peregudov AS, Auner N, Katsoulis DE (2002) Synthesis and properties of stereoregular cyclic polysilanols: cis- $[\mathrm{PhSi}(\mathrm{O}) \mathrm{OH}]_{4}$, cis- $[\mathrm{PhSi}(\mathrm{O}) \mathrm{OH}]_{6}$, and tris-cis-tris-trans- $[\mathrm{PhSi}(\mathrm{O}) \mathrm{OH}]_{12}$. Inorg Chem 41:6892-6904

28. Pozdnyakova YuA, Korlyukov AA, Kononova EG, Lyssenko KA, Peregudov AS, Shchegolikhina OI (2010) Cyclotetrasiloxanetetrols with methyl groups at silicon: Isomers all-cis- and cis-trans-cis-[MeSi $(\mathrm{O}) \mathrm{OH}]_{4}$. Inorg Chem 49:572-577

29. Graton J, Berthelot M, Laurence Ch (2001) Hydrogen-bond basicity $\mathrm{pK}_{\mathrm{HB}}$ scale of secondary amines. J Chem Soc Perkin Trans 2:2130-2135

30. Park JW, Park YJ, Jun ChH (2011) Post-grafting of silica surfaces with pre-functionalized organosilanes: new synthetic equivalents of conventional trialkoxysilanes. Chem Commun 47:4860-4871

31. Grzelka A, Chojnowski J, Cypryk M, Fortuniak W, Hupfield PC, Taylor RG (2002) Polycondensation and disproportionation of an oligosiloxanol in the presence of a superbase. J Organomet Chem 660:14-26

32. Mazurek M, Chojnowski J (1977) Anionic-polymerization of siloxanes. 2. Internal multifunctional assistance of siloxane system to siloxane bond-cleavage by alkali-metal silanolates. Makromol Chem 178:1005-1017

33. Dittmar U, Marsmann HC, Rikowski E (2008) Silsesquioxanes as Crown Ether Analogs. In: Auner N, Weis J (eds) Organosilicon 
chemistry set: From molecules to materials. Wiley-VCH Verlag $\mathrm{GmbH}$, Weinheim

34. Chojnowski J, Kaźmierski K, Rubinsztajn S, Stańczyk W (1986) Transformation of oligodimethylsiloxanols in the presence of a strong base - reactivity enchancement of the siloxane bond by the adjacent hydroxyl group. Makromol Chem 187:20392052
35. Shragin DI, Kopylov VM, Ivanov PV, Sokol'skaya IB (2008) Anionic copolymerization of alpha,omegadihydroxyoligodimethylsiloxane with organocyclosiloxanes. Polym Sci Ser A 50:31-36

36. Fina A, Tabuani D, Carniato F, Frache A, Boccaleri E, Camino G (2006) Polyhedral oligomeric silsesquioxanes (POSS) thermal degradation. Therm Acta 440:36-42 